\title{
Evaluation of three methods using deoxyribonuclease production as a screening test for Serratia marcescens
}

\author{
W. A. BLACK, R. HODGSON, AND ANN MCKECHNIE \\ From the University Department of Bacteriology, Royal Infirmary, Glasgow
}

SYNOPSIS Deoxyribonuclease (DNase) produced by Serratia marcescens is a characteristic feature which is useful in distinguishing this organism from closely related members of the Enterobacteriaceae. In an assessment of three methods of performing the DNase test as a screening procedure for Serratia marcescens, the conclusion was reached that the standard test was most suitable for use in the clinical bacteriology laboratory.

Since it is now well established that Serratia marcescens must be accepted as a pathogen (Ewing, Johnson, and Davis, 1962; Dodson, 1968; Alexander, Reichenbach, and Merendino, 1969) and that only $26.6 \%$ of strains are capable of producing pigment (Ewing et al, 1962), it has become increasingly important in recent years for the bacteriology laboratory positively to identify Serrutia marcescens in clinical material and to distinguish this organism from closely related non-pigmented members of the Klebsiella-Enterobacter-Serratia (K-E-S) group of the Enterobacteriaceae. In practice, this differentiation is usually made on the ability of Serratia marcescens to liquefy gelatin rapidly, and on its inability to ferment arabinose, raffinose, or rhamnose (Edwards and Ewing, 1962). The demonstration, however, that deoxyribonuclease (DNase) production is a characteristic of Serratia marcescens but not of the other members of the K-E-S division (Rothberg and Swartz, 1965; Elston and Elston, 1968) represented a major advance in the biochemical identification of this group since it meant that, for the first time, there was available a test which was sufficiently specific and straightforward to be of value as a screening procedure. Recently some modifications of the original test have been suggested (Schreier, 1969; Smith, Hancock, and Rhoden, 1969), and, since in this laboratory for the past few months we have been engaged in determining the exact incidence of Serratia marcescens in our clinical material (Black and Hodgson, 1970), it was thought that this presented an ideal opportunity for comparing the usefulness of the original test and these two modifications in the bacteriological identification of Serratia marcescens.

Received for publication 20 August 1970.

\section{Materials and Methods}

The survey was carried out in a Glasgow 800-bed teaching hospital over a four-month period during which a total of 497 Gram-negative bacilli isolated from 20,500 clinical specimens were tested for DNase production by the methods to be described.

The organisms included 221 strains which appeared as non-lactose fermenters on MacConkey's medium and which were fully identified biochemically (Black and Hodgson, 1970). The remaining 276 organisms, which were lactose-fermenters on MacConkey's medium, were screened initially for DNase production, the intention being to investigate fully any strains giving a positive or weak positive result.

Three methods of detecting DNase production by the test organisms were studied:

\section{THE STANDARD TEST (OXOID)}

The standard test, based on the method of Jeffries, Holtman, and Guse (1957), was carried out using Oxoid DNase agar (CM 321). After incubation, the surface of the plates was flooded with $1 \mathrm{~N} \mathrm{HCl}$ which forms a cloudy precipitate with the DNA in the medium. Production of DNase results in hydrolysis of the DNA into nucleotide fractions which are not precipitated by acid, this being demonstrated by a clear zone surrounding the DNase producing colonies.

\section{SCHREIER'S MODIFICATION (TOLUIDINE BLUE)}

The second test was based on the modification proposed by Schreier (1969). Toluidine blue (G. T. Gurr Ltd, London, NW9) was added to Oxoid DNase 
agar to give a final dye concentration of $0.01 \%$, the resulting dye-DNA complex producing a clear blue medium. If DNase is produced by the organism, this complex is broken down and the zone surrounding the colony changes colour from clear blue to rosepink.

\section{MODIFICATION OF SMITH et al (1969) (METHYL GREEN)}

The third test was essentially that described by Smith et al (1969). Methyl green (G. T. Gurr Ltd, London, NW9) was added to Oxoid DNase agar to give what was found to be a final optimal dye concentration of $0.02 \%$. The dye combines with the DNA to form a stable complex producing a green

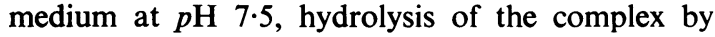
DNase resulting in freeing of the methyl green with the production of a clear zone surrounding the colonies producing the enzyme.

Neither of these modifications requires the addition of $1 \mathrm{~N} \mathrm{HCl}$ to the plates after incubation.

For each of the three media the test was performed in the same way, namely, a pure culture of the test organism was spot-inoculated on to the DNase test plates using a straight wire and the plates were incubated for about 18 hours at $37^{\circ} \mathrm{C}$. Using this method, it is possible to test up to 52 colonies on any one plate. A pigmented strain of Serratia marcescens and a strain of Escherichia coli which did not produce DNase were included as controls on every plate.

\section{Results}

These are shown in detail in Tables I and II where it $\overrightarrow{\vec{F}}$ can be seen that a total of 21 organisms gave either a positive $(+)$ or a weak positive $(+/-)$ reaction on at least one test medium.

Of the 15 positive results obtained using the standard (Oxoid) test medium, 12 positives were given by Serratia marcescens, two by Proteus ${ }^{\infty}$ vulgaris, and one by Aeromonas formicans. Using $\vec{O}$ the toluidine blue and methyl green methods, the positive results obtained corresponded exactly with $\vec{\omega}$ those given by the standard techniques, except that one of the Proteus species (no. 164) yielded only a weak positive reaction when tested on these modified + media.

Apart from Proteus vulgaris no. 164, weak positive $\frac{\omega}{\omega}$ results were given by six organisms, namely, two Proteus mirabilis species, two Alkaligenes species, and two species of Enterobacter liquefaciens. $\mathrm{As}_{3}$ shown in Table I, with the exception of one of the strains of Enterobacter liquefaciens (no. 95) which was negative by the standard technique but weakly positive by the other methods, weak positive results. were given either by the standard test alone or by all three methods.

\section{Discussion}

Before any test gains widespread acceptance as $\mathrm{a} \overrightarrow{\vec{O}}$

\begin{tabular}{|c|c|c|c|c|}
\hline \multirow{2}{*}{$\begin{array}{l}\text { Reference } \\
\text { Number }\end{array}$} & \multirow[t]{2}{*}{ Identity } & \multicolumn{3}{|l|}{ Deoxyribonuclease Production } \\
\hline & & Standard Method (Oxoid) & Toluidine Blue Modification & Methyl Green Modification \\
\hline 7 & Alkaligenes bronchisepticus & $+1-$ & $+1-$ & $+1-$ \\
\hline 45 & Serratia marcescens & + & + & + \\
\hline 55 & Proteus mirabilis & $+1-$ & - & - \\
\hline 63 & Serratia marcescens & + & + & + \\
\hline 66 & Alkaligenes bronchisepticus & $+1-$ & - & - \\
\hline 95 & Enterobacter liquefaciens & - & $+1-$ & $+1-$ \\
\hline 113 & Enterobacter liquefaciens & $+1-$ & $+1-$ & $+1-$ \\
\hline 122 & Proteus mirabilis & $+1-$ & - & - \\
\hline $137^{1}$ & Serratia marcescens & + & + & $\psi$ \\
\hline 164 & Proteus vulgaris & + & $+1-$ & $+1-$ \\
\hline $166^{1}$ & Serratia marcescens & + & + & + \\
\hline $177^{1}$ & Serratia marcescens & + & + & + \\
\hline $183^{1}$ & Serratia marcescens & + & + & + \\
\hline 194 & Serratia marcescens & t- & + & + \\
\hline 200 & Serratia marcescens & + & + & + \\
\hline 213 & Serratia marcescens & + & + & + \\
\hline $216^{2}$ & Serratia marcescens & + & + & + \\
\hline 244 & Aeromonas formicans & + & + & + \\
\hline 245 & Proteus vulgaris & + & + & + \\
\hline
\end{tabular}

Table I Organisms producing deoxyribonuclease on the three test media

${ }^{1}$ Isolated from the same patient (McL) on different occasions

${ }^{2}$ Isolated from the same patient (McK) on different occasions

+ Zone of clearing greater than $2 \mathrm{~mm}$ from edge of colony

+1 -Zone of clearing less than $2 \mathrm{~mm}$ from edge of colony

- No zone of clearing 


\begin{tabular}{|c|c|c|c|c|c|c|c|c|c|c|}
\hline \multirow[t]{3}{*}{ Group } & \multirow{3}{*}{$\begin{array}{l}\text { Number of } \\
\text { Isolates }\end{array}$} & \multicolumn{9}{|c|}{ Deoxyribonuclease Activity } \\
\hline & & \multicolumn{3}{|c|}{$\begin{array}{l}\text { Standard Method } \\
\text { (Oxoid) }\end{array}$} & \multicolumn{3}{|c|}{$\begin{array}{l}\text { Toluidine Blue } \\
\text { Modification }\end{array}$} & \multicolumn{3}{|c|}{$\begin{array}{l}\text { Methyl Green } \\
\text { Modification }\end{array}$} \\
\hline & & + & $+1-$ & - & + & $+1-$ & - & + & $+1-$ & - \\
\hline Serratia marcescens & 12 & 12 & - & - & 12 & - & - & 12 & 一 & - \\
\hline Enterobacter cloacae & 19 & - & - & 19 & - & 一 & 19 & - & - & 19 \\
\hline Enterobacter hafniae & 6 & - & - & 6 & - & - & 6 & - & - & 6 \\
\hline Enterobacter aerogenes & 5 & - & - & 5 & - & - & 5 & - & - & 5 \\
\hline Enterobacter liquefaciens & 1 & - & - & 1 & - & 1 & - & - & 1 & - \\
\hline Klebsiella & 13 & - & - & 13 & - & - & 13 & - & - & 13 \\
\hline Esch. coli & 62 & - & & 62 & - & - & 62 & - & - & 62 \\
\hline Proteus & 40 & 2 & 2 & 36 & 1 & 1 & 38 & 1 & 1 & 38 \\
\hline Providence & 5 & - & - & 5 & - & 一 & 5 & - & - & 5 \\
\hline Salmonella typhimurium & 4 & - & - & 4 & - & 一 & 4 & - & 一 & 4 \\
\hline Pseudomonas & 15 & - & - & 15 & - & - & 15 & 一 & 一 & 15 \\
\hline Alkaligenes & 12 & - & 2 & 10 & - & 1 & 11 & - & 1 & 11 \\
\hline Acinetobacter & 16 & - & - & 16 & - & - & 16 & 一 & - & 16 \\
\hline Aeromonas & 2 & 1 & - & 1 & 1 & - & 1 & 1 & - & 1 \\
\hline Flavobacterium & 2 & - & 一 & 2 & - & - & 2 & - & 一 & 2 \\
\hline Unclassified & $7^{1}$ & - & - & 7 & - & 一 & 7 & - & - & 7 \\
\hline \multirow{4}{*}{$\begin{array}{l}\text { Total (all non-lactose fermenters on } \\
\text { MacConkey) } \\
\text { Miscellaneous Gram-negative bacilli (all } \\
\text { lactose fermenters on MacConkey) }\end{array}$} & & & & & & & & & & \\
\hline & 221 & 15 & 4 & 202 & 14 & 3 & 204 & 14 & 3 & 204 \\
\hline & & & & & & & & & & \\
\hline & 276 & - & $1^{2}$ & 275 & - & $1^{2}$ & 275 & - & $1^{2}$ & 275 \\
\hline
\end{tabular}

Table II Screening of 497 Gram-negative bacilli for deoxyribonuclease production

${ }^{1}$ Mostly members of the Achromobacteraceae which did not readily fit into a genus

${ }^{2}$ No. 113 in Table I

screening method it has to satisfy certain basic criteria. First of all the expected result must be of sufficient value to justify the extra effort expended; secondly, it must be a sensitive test, so as to eliminate any possibility of false-negative results; thirdly, it must be specific, for, if too many false positives are collected, the value of the screen is minimized; and lastly, it must be technically simple to perform so as to make its use applicable to the busy routine laboratory. The three methods of detecting production of DNase will therefore be considered with these four criteria in mind.

Several recent publications have emphasized the role of Serratia marcescens as a pathogen, especially in debilitated patients (Dodson, 1968; Altemeir, Culbertson, Fullen, and McDonough, 1969). It has, moreover, been encountered in hospital as a contaminant of peritoneal dialysis fluid (McCracken and Lipscomb, 1965), of banked blood (Black, Pollock, and Batchelor, 1967), and of ultrasonic nebulizers (Ringrose, McKown, Felton, Barclay, Muchmore, and Rhodes, 1968); in all of these instances, severe, and in two of the cases fatal, infection of patients followed. Despite the fact that this organism does not appear to be so common in this country as in the USA (Black and Hodgson, 1970), it has been implicated in two fatalities in the UK in recent years (McCracken and Lipscomb, 1965; Black et al, 1967) and, with the rising incidence in Gram-negative infections in hospitals (Barber, 1961;
Barrett, Casey, and Finland, 1968; DuPont and Spink, 1969), there is little doubt that it will be seen more and more frequently. It is felt, therefore, that it is justifiable to advocate the DNase test as one of the essential items in any set of screening procedures for Gram-negative bacilli, particularly those appearing as non-lactose fermenters, as it is otherwise very difficult to separate Serratia marcescens from the closely related Enterobacter species.

The sensitivity of all three techniques is shown to be satisfactory in Table I, Serratia marcescens giving a strong positive reaction in every case.

If positive reactions alone are considered, then the specificity of the test is constant for all three methods except that only the Oxoid method gave a positive reaction for Proteus no. 164. The fact that three organisms apart from Serratia, namely, two Proteus species and one Aeromonas, gave positive reactions does not seriously detract from the value of the test as these organisms were very easily distinguishable from Serratia by other means. As distinct from the positive reactions, the production of weak positive reactions varied with the media and, as is shown in Table I, the standard (Oxoid) method was, apart from the results given by Enterobacter liquefaciens no. 95, more sensitive but less specific than the two modifications. Once again, the production of weak positive reactions by Proteus and Alkaligenes species is relatively unimportant but it was surprising to find this type of 
reaction given by both Enterobacter liquefaciens strains tested as this has not been mentioned by other workers (Rothberg and Swartz, 1965; Elston and Elston, 1968). These weak positive reactions were, however, easily distinguishable from those given by Serratia marcescens.

For the purposes of this study, the standard test was found to be preferable to the two modifications although it was appreciated that the latter may have a part to play in other circumstances (Smith et al, 1969). Our experience with the methyl green medium of Smith et al (1969) is that it is technically difficult to prepare and that DNase production is shown much less clearly than by either of the other two methods. Although the toluidine blue modification of Schreier (1969) gave excellent results which were easy to interpret, we were unable to agree with her that this test was superior to the standard method. Some allowance, however, can possibly be made for the fact that we obtained our commercial media from different manufacturers.

In the final analysis, our preference for the standard method was based on the fact that the medium was easy to prepare and the results were clear-cut. Criticism of this technique has been based on the fact that results are irreproducible and equivocal (Schreier, 1969) and that, because IN HCl has to be added to the test plate, this precludes further incubation (Smith et al, 1969). As already stated, we cannot agree with Schreier on the first point and, as regards the second, if the DNase test is to be used as a screening procedure for Serratia in the identification of pure isolates of Gram-negative bacilli then the question of reincubation is irrelevant as large colonies are invariably produced by the Enterobacteriaceae after 18 hours' incubation.

In conclusion, therefore, it is felt that the DNase test for Serratia is of considerable value and that, if the standard method is adopted, it is well within the scope of every laboratory interested in the identifica $\stackrel{0}{\overrightarrow{2}}$ tion of Gram-negative bacilli.

\section{References}

Alexander, R. H., Reichenbach, D. D., and Merendino, K. A. (1969) Serratia marcescens endocarditis. Arch. Surg., 98, 287-291.

Altemeier, W. A., Culbertson, W. R., Fullen, W. D., and McDonough J. J. (1969). Serratia marcescens septicaemia. Arch. Surg., 99 $232-238$ Barber, M. (1961). Hospital infection yesterday and today. J. clin $\overrightarrow{0}$
Path., 14, 2-10.

Barrett, F. F., Casey, J. I., and Finland, M. (1968). Infections and antibiotic use among patients at Boston City Hospitalcu February, 1967. New Engl. J. Med., 278, 5-9.

Black, W. A., and Hodgson, R. (1970). Search for serratia. (I preparation.)

Black, W. A., Pollock, A., and Batchelor, E. L. (1967). Fatal transiv fusion reaction due to Serratia marcescens. J. clin. Path., 20 883-886.

Dodson, W. H. (1968). Serratia marcescens septicaemia. Arch. intern Med., 121, 145-150.

DuPont, $H$. negative organisms: An analysis of 860 patients with bac teremia at the University of Minnesota Medical Center, 19581966. Medicine (Baltimore), 48, 307-332.

Edwards, P. R., and Ewing, W. H. (1962). Identification of Entero bacteriaceae, 2nd ed. Burgess, Minneapolis.

Elston, H. R., and Elston, J. H. (1968). Further use of deoxyribo $\overrightarrow{-1}$ nuclease in a screening test for serratia. J. clin. Path., 21, 210 212.

Ewing, W. H., Johnson, J. G., and Davis, B. R. (1962). The Occurrence of Serratia marcescens in Nosocomial Infections. US Depart ment of Health, Education and Welfare, Washington, DC.

Jeffries, C. D., Holtman, D. F., and Guse, D. G. (1957). Rapid metho for determining the activity of microorganisms on nuclei $\bar{D}$ acids. .J. Bact., 73, 590-591.

McCracken, A. W., and Lipscomb, F. E. (1965). Serratia marcescen infection complicating peritoneal dialysis. Brit. med. J., 1 웅 1536-1537.

Ringrose, R. E., McKown, B., Felton, F. G., Barclay, B. O., Much음 more, H. G., and Rhodes, E. R. (1968). A hospital outbreak of Serratia marcescens associated with ultrasonic nebuliser? Ann. intern. Med., 69, 719-729.

Rothberg, N. W., and Swartz, M. N. (1965). Extracellular deoxyribosnucleases in members of the family enterobacteriaceae. $\bar{\sigma}$ Bact., 90, 294-295.

Schreier, J. B. (1969). Modification of deoxyribonuclease test mediurळ for rapid identification of Serratia marcescens. Amer. J. clin Path., 51, 711-716.

Smith, P. B., Hancock, G. A., and Rhoden, D. L. (1969). Improve@ medium for detecting deoxyribonuclease-producing bacteria Appl. Microbiol., 18, 991-993. 